\title{
Analysis on Stress Distribution of the Piston Rod and the Bush while Cylinder Impact
}

\author{
Dongyun Guo ${ }^{1, a^{*}}$, Tao Wang ${ }^{2, b}$
}

School of Automation,Beijing Institute of Technology,

Beijing 100081,China

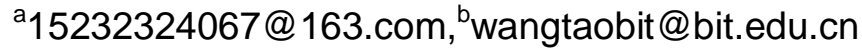

Keywords: stress; deformation; cylinder impact; piston rod; bush

Abstract: The repeated movement between the piston rod and the barrel during the process of cylinder impact will lead to leak and shorten the life of the cylinder. In order to research the distribution of dynamic stress and deformation of the piston rod and the bush when the piston rod suddenly stops at the end of the cylinder with different speeds and different loads, it's necessary to analysis the system by the model simulation. This paper mainly discusses the condition that cylinder works with the load of $50 \sim 100 \mathrm{~N}$, the piston rod speeds of $500 \sim 1000 \mathrm{~mm} / \mathrm{s}$ by using the transient kinetic module of ANSYS/workbench. Simulation results show that higher speed or heavy load will cause the significantly increased stress suffered by the various parts of the system and its deformation is relatively obvious.

\section{Introduction}

\section{Research background}

Nowadays, Cylinder is widely used in various fields and plays an important role in industrial production, So it's of great practical significance to effectively improve cylinder's life and efficiency $^{[1]}$. The repeated impact between the piston rod and the barrel will lead to leak and wear, which may result in leak and shorten the life of the cylinder, so have a deep study of the stress distribution and deformation condition is very important. The static effect between the piston rod and the bush was already calculated, but the dynamic stress produced when the piston rod suddenly stops at the end of the cylinder has not been studied, Therefore, It's needed to make a further study. This paper mainly focuses on the distribution of stress when the piston impact on the end of the cylinder. The velocity of piston, lateral load on the piston rod, the space between the piston rod and bush are major factors, so it's necessary to study the stress distribution with these different factors.

\section{Research methods}

The paper use simulation system to study the stress distribution in cylinder impact, and the model analysis is carried on ANSYS/Workbench, which is widely used. Specific research programs include:

(1) According to the actual situation, establish the entity model of cylinder in ANSYS/workbench;

(2) Analysis cylinder modal in the transient dynamics of ANSYS/workbench ;

(3) Setting boundary conditions according to the objective requirements, find the optimal boundary condition that closest to the actual situation;

(4) Analysis the cylinder under different load, different speeds; 
(5) Post processing in ANSYS/workbench, observing the stress distribution, deformation, and analyzing the results ${ }^{[2]}$.

\section{Introduced model}

\section{Model}

The cylinder model that currently used is a simplified model, all the cylinder include cylinder tube, piston rod, bush, sealing ring, piston, end cover and so on, the diameter is $32 \mathrm{~mm}$, stroke is $0.1 \mathrm{~m}$, the space between the piston rod and bush is $0.06 \mathrm{~mm}$, the cylinder mode is shown in the figure below.

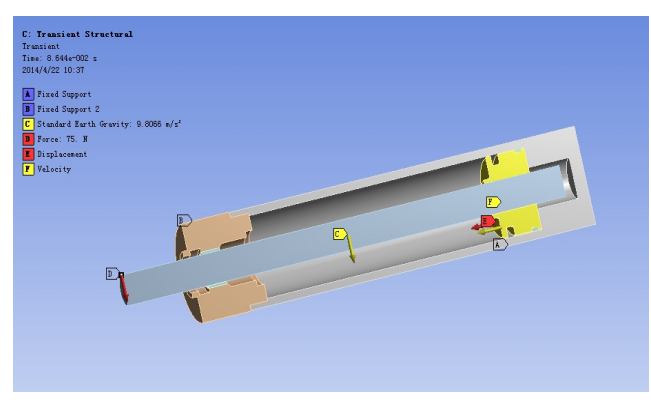

Fig.1 The 3D model of cylinder

\section{Contact set}

The model consists of seven contact surfaces, The figure below is the definition of contact type.

Table 1 Definition of contact type.

\begin{tabular}{|c|c|}
\hline Contact element & Contact type \\
\hline end cover-bush & Bonded \\
\hline end cover_cylinder tube & Bonded \\
\hline bush—piston rod & Frictionless \\
\hline piston rod—piston & Bonded \\
\hline piston—sealing ring & Bonded \\
\hline piston—cylinder tube & Frictionless \\
\hline sealing ring-cylinder tube & Frictionless \\
\hline
\end{tabular}

\section{Mesh}

The mesh quality can directly affect the calculation results, so the more detailed the better, firstly the mesh size is set to $0.005 \mathrm{~m}$, secondly using the partition refinement mesh, because the cylinder model is 3D model, so the mesh is divided automatically, the mesh is mostly constituted with hexahedral, In some uneven part may have some tetrahedron. After that the number of cells and the number of nodes increases obviously, which helps to improve the quality of mesh. In order to improve the impact accuracy, reduces the mesh size in the piston and the end cover ${ }^{[3]}$, mesh shown in the below figure: 


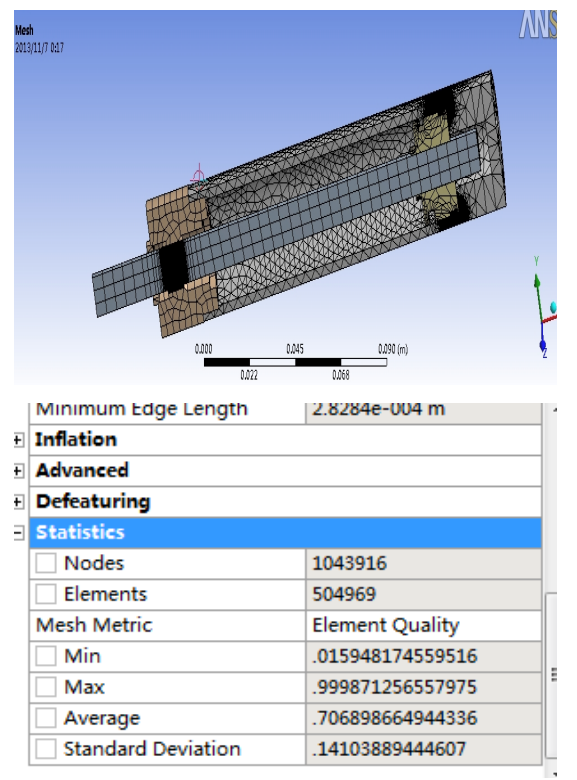

Fig.2 Mesh of the system

\section{Earth gravity set}

By adding standard earth gravity, and date of each component's size, computer can calculate the volume of the piston rod and the piston, and load the element of gravity to the system, which makes the system more close to the actual situation ${ }^{[4][5]}$.

\section{Simulation analysis}

\section{The simulation results under different impact velocities}

The study use $1000 \mathrm{~mm} / \mathrm{s}, 500 \mathrm{~mm} / \mathrm{s}$ two different speed load to simulate the impact situation with different velocity that between cylinder piston and piston rod, the load is set at $0 \mathrm{~N}$, the space of bush and piston rod is $0.06 \mathrm{~mm}$, study on the stress distribution that influenced by different impact speed, and carries on the contrast.

The stress distribution under $1000 \mathrm{~mm} / \mathrm{s}$

Setting the velocity at $1000 \mathrm{~mm} / \mathrm{s}$. Cylinder stroke in the model is $100 \mathrm{~mm}$, the solution time is set to $0.1 \mathrm{~s}$. The relationship curve of speed and time is shown blow. The impact solution on the bush shown in figure 3.

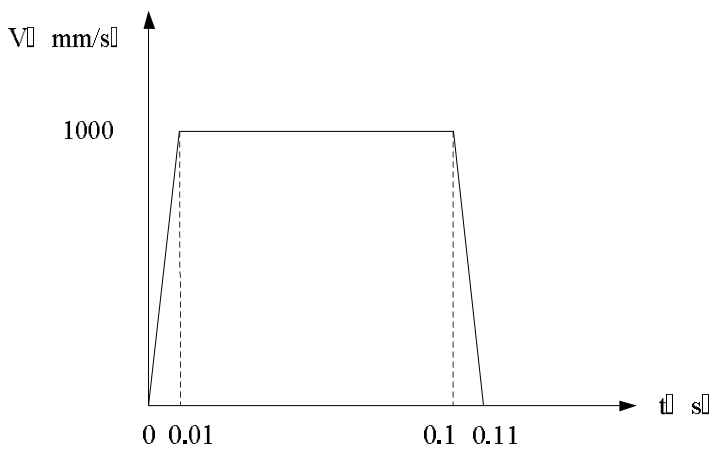

Fig.3 The relationship curve of speed and time under $1000 \mathrm{~mm} / \mathrm{s}$ 


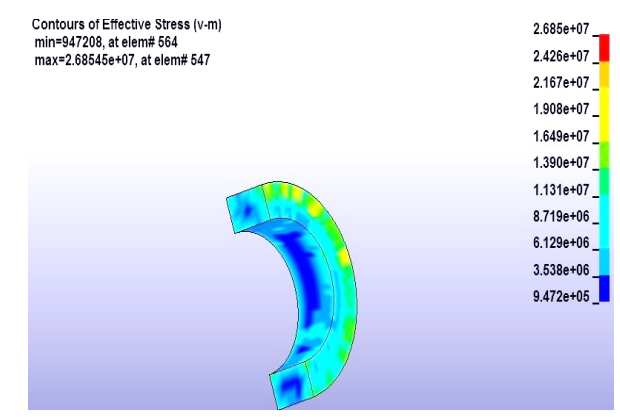

Fig.4 Stress distribution on bush when impact occur under $1000 \mathrm{~mm} / \mathrm{s}$

In the first moment of collision, the stress mostly concentrate the on inner surface of bush, the maximum stress is 10MPa. It can be seen from Figure 4 that, when a collision occurs, the stress on the piston rod and bush occur surge, and the bushing stress distribution changes, It mostly occur on the posterior surface of bush. and the maximum stress is $27 \mathrm{MPa}$.

The stress distribution under $500 \mathrm{~mm} / \mathrm{s}$

In order to compare the simulation result with the condition of $1000 \mathrm{~mm} / \mathrm{s}$, there also showed the stress distribution of $500 \mathrm{~mm} / \mathrm{s}$.

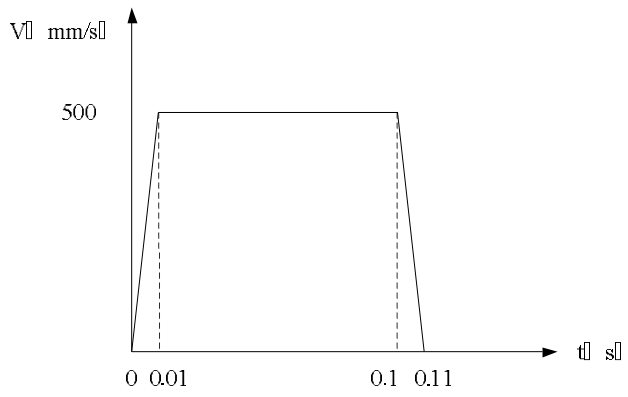

Fig.5 The relationship curve of speed and time under $500 \mathrm{~mm} / \mathrm{s}$

The stress distribution is shown as blow.

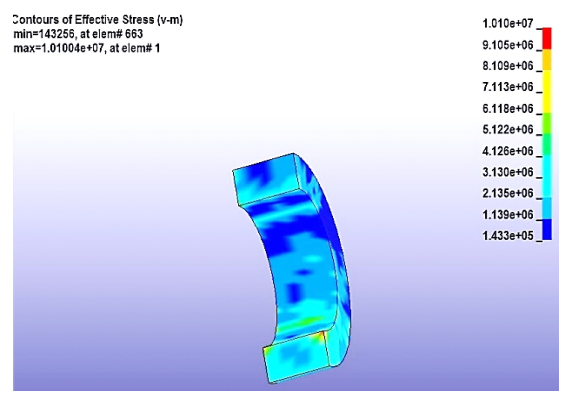

Fig.6 Stress distribution on bush when impact occur under $500 \mathrm{~mm} / \mathrm{s}$

In the first moment of collision, the stress is also mostly concentrate the on inner surface of bush, the maximum stress is $8.7 \mathrm{MPa}$. It can be seen from Figure 6 that, maximum stress is $10 \mathrm{MPa}$. 
The study above shows that under different speed the stress distribution on the bush is similar, but under $1000 \mathrm{~mm} / \mathrm{s}$ the stress is lager than the $500 \mathrm{~mm} / \mathrm{s}$ situation. So a higher speed will produce a lager stress.

\section{The simulation results with different load}

After setting up the simulation conditions, the load is set at $75 \mathrm{~N}$ and $100 \mathrm{~N}$ on the top of the bush, the space of bush and piston rod is $0.06 \mathrm{~mm}$, the velocity set at $1000 \mathrm{~mm} / \mathrm{s}$, study on the stress distribution that influenced by different load, and carries on the contrast.

The stress distribution with $75 \mathrm{~N}$

The paper mainly study on the stress distribution of bush and piston rod, so there we respectively intercept three moment on the impact process to observe the stress distribution of them. As it can be see from the blow figures, with the continuous movement of the piston rod, the stress of bush increases, at the same time, stress of the piston rod is becoming larger and larger.

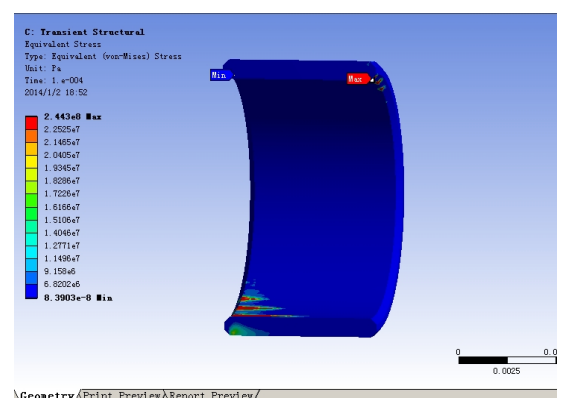

Fig.7 The initial time of bush with $75 \mathrm{~N}$ load

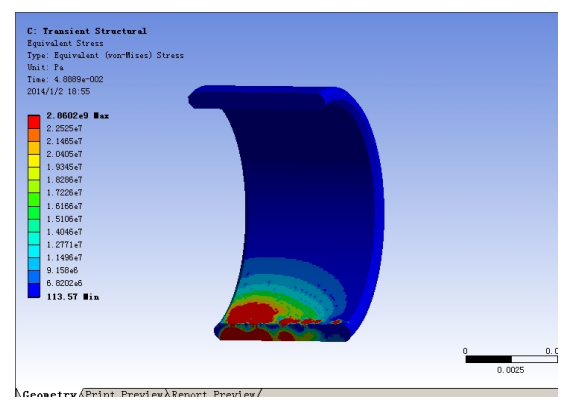

Fig. 8 The middle time of bush with $75 \mathrm{~N}$ load

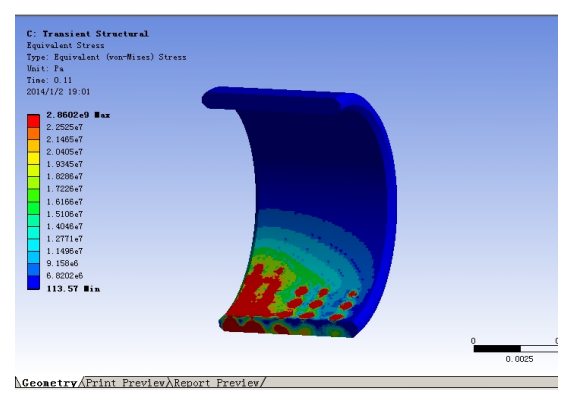

Fig.9 The impact time of bush with $75 \mathrm{~N}$ load 


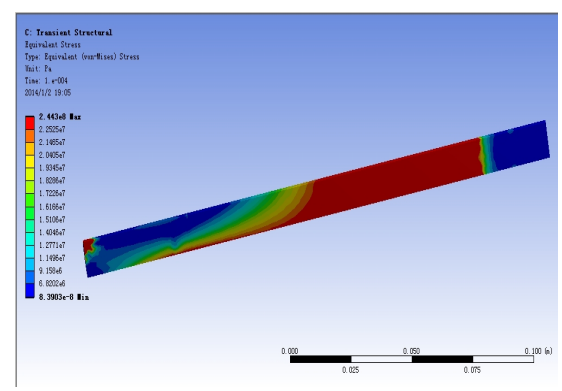

Fig.10 The initial time of piston rod with $75 \mathrm{~N}$ load

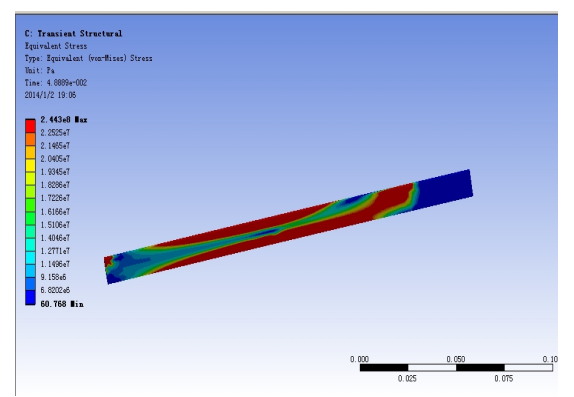

Fig.11 The initial time of piston rod with $75 \mathrm{~N}$ load

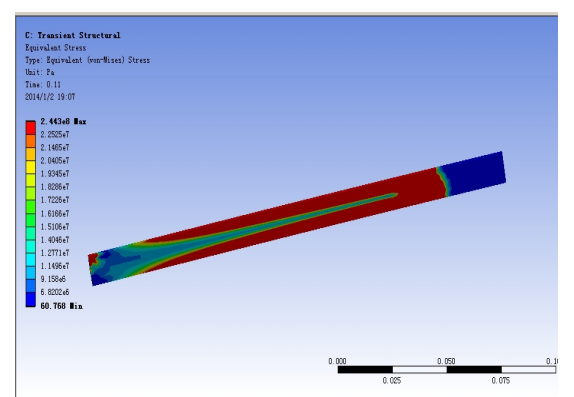

Fig. 12 The initial time of piston rod with $75 \mathrm{~N}$ load

Below is the description of the bush and piston rod, The figure 11 show that, when load is $75 \mathrm{~N}$, the maximum description of bush along the vertical direction is $1.04 \times 10^{-5} \mathrm{~m}$, the maximum description of piston rod is $9.60 \times 10^{-4} \mathrm{~m}$.

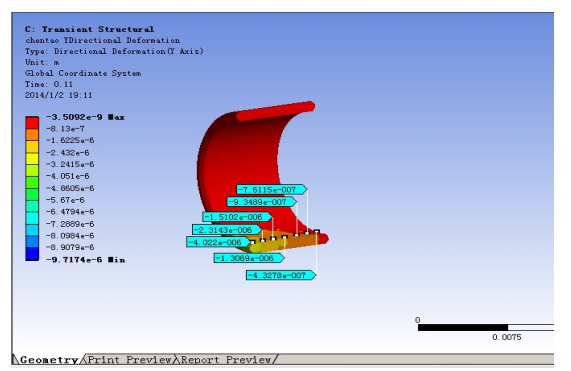

Fig. 13 The description of bush with $75 \mathrm{~N}$ load 


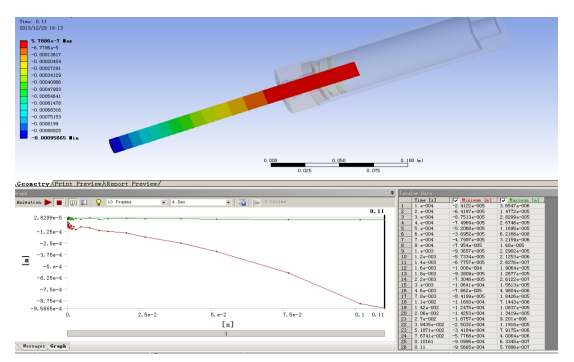

Fig.14 The description of piston rod with $75 \mathrm{~N}$ load

The stress distribution with $100 \mathrm{~N}$

Under the load of $100 \mathrm{~N}$, the stress distribution is similar to $75 \mathrm{~N}$, but it is larger. As below also respectively intercept three moment on the impact process to observe the stress distribution of the bush and piston rod.

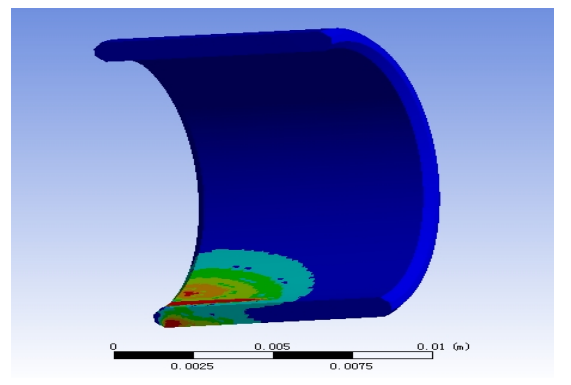

Fig. 15 The initial time of bush with $100 \mathrm{~N}$ load

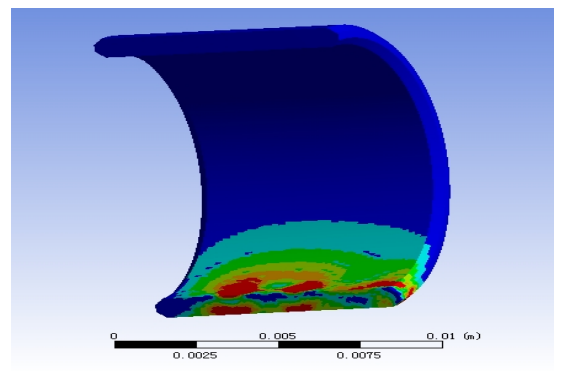

Fig.16 The middle time of bush with $100 \mathrm{~N}$ load

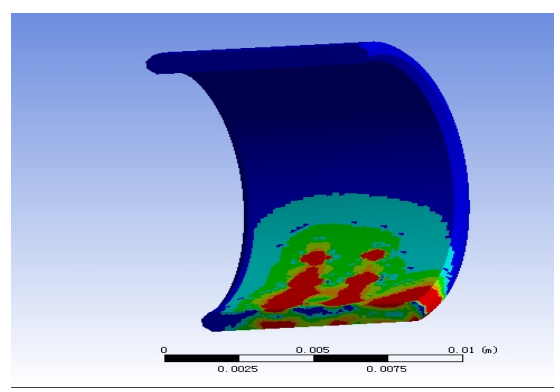

Fig. 17 The impact time of bush with 100N load 


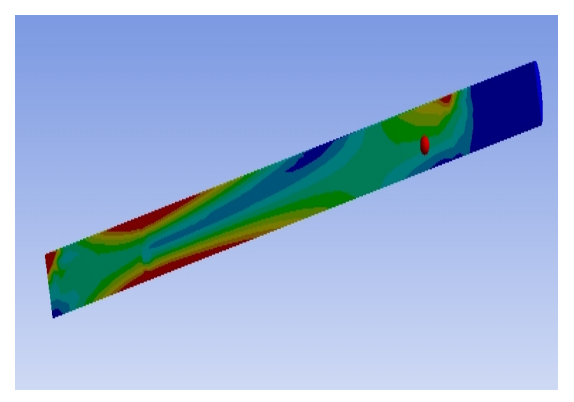

Fig.18 The initial time of piston rod with $100 \mathrm{~N}$ load

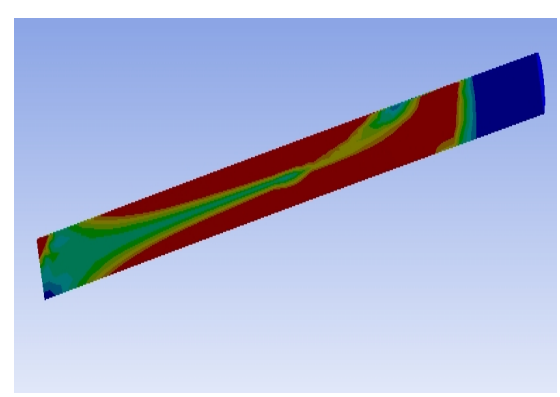

Fig.19 The initial time of piston rod with $100 \mathrm{~N}$ load

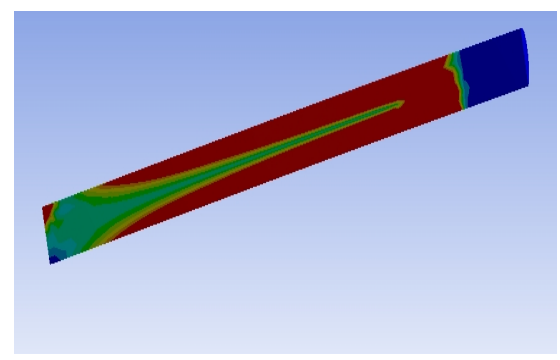

Fig.20 The initial time of piston rod with $100 \mathrm{~N}$ load

Below is the description of the bush and piston rod, figure 18 show that, when load is $100 \mathrm{~N}$, the maximum description of bush along the vertical direction is $2.40 \times 10^{-5} \mathrm{~m}$, the maximum description of piston rod is $1.30 \times 10^{-3} \mathrm{~m}$.

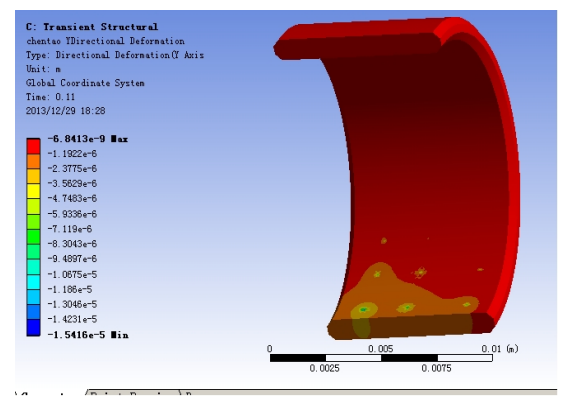

Fig. 21 The description of bush with $100 \mathrm{~N}$ load 


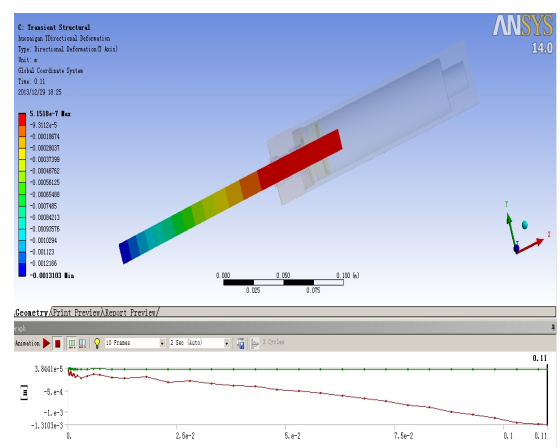

Fig.22 The description of bush piston rod with $100 \mathrm{~N}$ load

The study above show that with different load the stress distribution on the bush is similar, but with $100 \mathrm{~N}$ load the stress is lager than the $75 \mathrm{~N}$ situation. The description is also more obvious, so a lager load will produce a lager stress and lager description.

\section{Conclusion}

The paper mainly analysis the distribution of dynamic stress and deformation of the piston rod and the bush when the piston rod suddenly stops at the end of the cylinder with different speeds and different loads, based on the above analysis, the stress distribution under different speed or different load is similar, the maximum stress increases with the speed increases and so to the load. And the values of maximum stress surged when the piston impact end cover, surged amplitude is also increases with the speed or load increases. so if people can be careful with the speed and load, it would effectively reduce wear and lengthen the life of cylinder.

\section{References}

[1] Birong Liu,Stress analysis of small diesel engine crankshaft based on ANSYS, Tractor \& Farm Transporter,2004,3, pp.30-33.

[2] Zhixing Huang, Chengzhu Liu, ANSYS Workbench14.0 super learning manual, People's Posts and Telecommunications Press,2013.

[3] Silva FS, Fatigue on engine pistons:a compendium of case studies [ J ] .Engineering Failure Analysis , 2006,13, pp.480-492 .

[4] Xiaoli Yu, Yajiao Wu ,Rui Huang,et al.CFD calculation and analysis of cooling jacket flow and heat transfer for car engine [ J ] . Vehicle Engine, 2010,3,pp.50 -55 .

[5] Wu Yi, Tang Lan,Temperature field analysis of engine heated parts based on finite element method, joumal of jiangsu university, 2012,33-6, pp.638-642. 